\title{
Relationship between advertising expenditures and earnings of the UK firms
}

\author{
Maqsood Iqbal Qureshi ${ }^{1, a}$ \\ ${ }^{\mathrm{a}}$ Gulf University of Science and Technology, Kuwait
}

\begin{abstract}
This article studies the asset value of the UK firms advertising expenditures by estimating the relation between advertising expenditures and earnings for a large cross-section of the UK firms for the period from 1999 to 2003 and reports that advertising expenditures are significantly correlated with earnings. The results indicate that advertising expenditures contribute to earnings afar the era these expenditures are incurred. These expenditures are positively significantly correlated with earnings at least up to four years after the year of the expenditure. Additionally, this article also examines the possible differential media advertising asset value effects on earnings and results do not appear to report asset value differences across electronic and print media advertising expenditures. The overall results of this study suggest positive contribution and long lived effects of advertising expenditures to earnings and hold important implications for policy makers and standard setters.
\end{abstract}

Keywords: advertising, intangible, earnings, media advertising

\section{JEL codes: M4}

\section{Introduction}

Firms spending in marketing and advertising have increased tremendously in recent years. The worth of international ad market is estimated at 537 billion U.S. dollars in 2017. According to the Advertising Association (AA)/WARC Expenditure Report the United States was the major ad market globally with an advertising spend of

\footnotetext{
${ }^{1}$ Department of Accounting, Gulf University of Science and Technology, P.O Box7207, Hawally 32093, Kuwait Email: Qureshi.M@gust.edu.kw
} 
197.4 billion U.S. dollars in $2017^{1}$. The United Kingdom (UK) stays fourth among the world's major advertising markets, and first among markets in Europe ${ }^{2}$. The UK experienced the eighth consecutive year of market growth and its advertising spending raised $4.6 \%$ to reach $£ 22.2 \mathrm{bn}$ in 2017 . Forecasts for the next two years indicate continued growth of $1.4 \%$ in 2018 and $3.8 \%$ in $2019^{3}$.

Advertising is a means of communication with variety of consumer groups. Advertising plays an important role in our economic system through its economic, social, marketing and communications functions. Chen and Allmon, (1998) assert "Advertising and promotions are an integral part of our social and economic system, evolving into a vital communications system that gives businesses and consumers the ability to deliver carefully prepared messages to target audiences". The firms incur advertising expenditures with expectations that these outlays will create sales and profit in the future. Confidence (2005) argues that advertising expenditure utilize current resources in anticipation of long-term benefits to the firm.

Research investigating the asset value of advertising expenditures provide contradictory evidence. For instance, where studies such as Hirschey and Weyganddt (1985); Chauvin and Hirschey (1993); Hirschey(1985); Hirschey and Spencer (1992); Notta and Oustapassidis (2001); Shah et al. (2009) and Qureshi $(2015,2017)$ support the view that advertising having an asset value there are other studies such as Reekie and Bhoyrub (1981); Bublitz and Ettredge (1989); Erickson and Jacobson (1992); Sougiannis (1994) and Core (2003) that do not support this.

The existing research on economic durability of advertising expenditures provide some evidence that supports short lived view of advertising but the evidence is inconclusive for the long lived view. Wyatt (2008) provides possible reasons for that mixed evidence and indicates the gaps in the literature. Wyatt (2008) further argues that these gaps in the research demand for investigation of the long-term effects of advertising expenditures, which have been limited thus far due to difficulties finding data.

In the UK information on advertising expenditures is only available from a commercial organization ACNielsen MEAL ${ }^{4}$. Shah et al. (2009) argue that lack of disclosure of data from the accounting system in the UK has limited research on advertising expenditure in the $\mathrm{UK}^{5}$. The firms do not report expenditures of intangibles separately in the financial statements and Wyatt (2000) argues that expenditure disclosures on intangibles are mainly limited to R\&D. Therefore, the research on intangibles is limited to certain expenditures and this contributed to the difficulty being experienced in assessing their contribution to firms' financial performance and value relevance. 
Advertising expenditures are not disclosed separately in annual financial reports under current GAAP that demands advertising activities to be immediately expensed. The current manifest accounting practice to consider advertising as a cost line item instead value generating activity decreases the earnings, on the one hand, and also results in the exclusion of a possible intangible asset from the financial reports, on the other. Nakamura (2005) argues that this practice understates profit in the short run and overstates in the long run. The debate on appropriateness of the current accounting treatment is still going on. If advertising creates intangible asset and provide long term benefits then to capitalize and subsequently amortize advertising spending systematically like that of tangible assets rather than expensing all spending once is more appropriate. The main purpose of this research is therefore, to examine the long-run relationship between advertising and earnings.

This study makes the following contributions to the literature. This study adds to the limited research available on asset value of advertising expenditures in the UK. In their study Shah et al. (2008) note that lots of the evidence on intangibles is from the US, and there appears to be relatively diminutive evidence on this issue in the UK. Our findings are important and hold implications for future standard setting in the UK and other countries re advertising recognition and disclosure in the financial statements where the immediate expensing of advertising investments rather than capitalization leads to accounting distortions such as downward bias in the value of assets, current earnings and shareholders' equity. Second, there has been little effort to examine the long term effects of advertising on earnings and this study looks at multi period instead of single-period effects of advertising. Wyatt (2008) argues that previous research focused primarily on value relevance in the short term and used single-period advertising models that limit scope of their findings. Third, prior studies examining effectiveness of the advertising expenditures has overlooked role of different advertising media in understanding value creation and durability of benefits from advertising. The previous research assumed homogenous effects of advertising and generally used total advertising expenditures, irrespective of the form of advertising medium used to communicate it. Nonetheless, each medium differs from each other in terms of efficiency, the information it delivers, the outlays related with it, the frequency of the messages and so on. A relevant question is then what is the effect of each medium on profitability of the firm. We answer this question by splitting advertising expenditures among electronic and print media advertising and analyze long-lived effect of each medium on earnings. If there are medium advantages in advertising, the different media advertising expenditures will possibly have different effects on the profitability of firms.

The rest of the paper is organized as follows. The following section offers a brief review of the literature. This is followed by discussions on data and the research approach. The next section presents estimation results. The final section provides summary of the research findings and directions for future research. 


\section{Literature review}

Earlier research on the asset value of advertising expenditures can be classified into studies of the advertising - sales, advertising - market value and advertising profitability relationship. Among the research of advertising effects on sales, Magna and Muller (1991); Elliott (2001); Yiannaka et al. (2002); Ouyang et al. (2002) and Zhou et al. (2003) offer evidence of an effect of advertising on sales. While Picconi (1977); Hula (1988) and Abbott et al. (1997), among others, indicate an insignificant effect of advertising on sales.

In the recent past a number of studies have used valuation models to examine the relation between market value and advertising expenditures of the firm. Research such as Hirschey (1982, 1985); Connolly and Hirschey (1984); Hirschey and Weyganddt (1985); Hirschey and Spencer (1992); Chauvin and Hirschey (1993); Shah et al. (2009); Joshi and Hanssens (2010); Qureshi (2015 and 2017) and Mcllkenny and Persaud (2017) report positively significant association between market value and advertising expenditures. On the contrary Core (2003) finds no effect of advertising on market value.

Advertising and profitability studies provide rather mixed results. Though some research report an advertising and profitability correlation (Notta \& Oustapassidis, 2001; Graham \& Frankenberger, 2000; Sougiannis, 1996; Porter, 1976); others are unable to find a significant association between advertising and profitability (e.g. Reekie \& Bhoyrub, 1981).

In their analysis Comanor and Wilson (1967) find a significantly positive relationship between the profit rates and the advertising/sales ratio. Their findings provide evidence that advertising causes profitability. Porter (1976) provide evidence that electronic and print media advertising have different implications for market performance. Porter finds significantly greater impact of television advertising on profitability than those for other types of advertising. In another study Hirschey (1978) reports a positive correlation between overall advertising and profitability. However, Hirschey (1978) finds significantly greater positive effect of television advertising on profitability than does advertising in general. In their study Sridhar et al. (2016) find a positive and significant effect of national, regional and online advertising on firm performance.

Nickell and Metcalf (1978) and Paton and Williams (1999) use U. K. sample and indicate a positive association between advertising and profitability. In their study Reekie and Bhoyrub (1981) using the UK data for the period from 1968 to 1977 could not find a significant relationship between advertisement and profitability. Lev and Sougiannis (1996) report an association between advertising expenditure and operating income. Lev and Sougiannis (1996, P120), insert that, “.... \$ \$1 advertising expenditure is associated with an operating income (before advertising) increase of roughly $\$ 1.00-1.60 "$ 
Graham and Frankenberger (2000) examine the impact of advertising expenditures on frim financial performance for a sample of 320 publically traded firms with reported advertising expenditures for 10 consecutive years. Their results indicate long-run relationship between advertising and both with future earnings and market values. Graham and Frankenberger (2000, p154) insert that, "...depending upon the type of product, changes in advertising expenditures are significantly associated with earnings up to 4 years following the year of the expenditures". Notta and Oustapassidis (2001) examine asset value of advertising for television (TV), radio, magazine and newspapers for 350 food manufacturing firms. They show that only TV advertising positively effects profitability.

\section{Data, research strategies and model development}

To investigate relation between advertising and earnings we use a model that is empirically an extension of that developed by Lev and Sougiannis (1996) and Graham and Frankenberger (2000). Lev and Sougiannis (1996) defines the earnings of firm $i$ in year $t, E_{i t}$, as a function of tangible, $\mathrm{TA}_{\mathrm{it}}$ and intangible assets, $\mathrm{IA}_{\mathrm{it}}$.

$\mathrm{E}_{\mathrm{it}}=\mathrm{g}\left(\mathrm{TA}_{\mathrm{it}}, \mathrm{IA}_{\mathrm{it}}\right)$

Where $\mathrm{g}$ denotes the earnings process, TA stands for tangible assets, and IA stands for intangible assets of firm $i$ in year $t$.

Though earnings, and tangible assets are stated in financial reports, the intangible capital, IA, is not stated except for specific intangible assets e.g. purchased goodwill and therefore has to be assessed. The existing primary accounting practice is to treat advertising and research and development (RD) as a single period expense. Recent research (e.g. Hirschey 1982,1985; Connolly \& Hirschey 1984, 1990; Hirschey \& Weygandt 1985; Chauvin \& Hirschey1993,1994 and Graham \& Frankenberger 2000) has extensively used various measures of intangibles such as RD and advertising expenditures as proxies to account for unrecognized intangible assets. Hirschey (1982) hypothesizes that current advertising and RD expenditures are indicators of future profitability and these outlays create intangible capital. Graham and Frankenberger (2000) argue that "...advertising and R\&D expenditures contribute to future earnings, it follows that earnings in any particular year are determined to some extent by both prior-year and current-year expenditures."

We can expand equation 1 as follow:

$E_{i t}=g\left(T A_{i t}, G W_{i t}, R D_{i t}, A D_{i t}\right)$

Where GW is goodwill, RD is research and development, and AD is advertising assets. Graham and Frankenberger (2000) contend that the asset value of advertising 
and RD expenditures is their contribution to future earnings. Following Lev and Sougiannis (1996) this research employ current year advertising and R\&D expenditures to surrogate for advertising and RD assets. Lev and Sougiannis (1996) and Graham and Frankenberger (2000) illustrate the RD asset as $\sum$ hi,t-k*RDi, t - k where hi, $-\mathrm{k}$ is the contribution of a dollar in $\mathrm{R} \& \mathrm{D}$ expenditure in year $\mathrm{t}-\mathrm{k}(\mathrm{k}=0$, $\ldots, n)$ to earnings in year $t$. The advertising asset is defined as $\sum v i, t-k^{*} A D i, t-k$ where $v i, t-k$ is the contribution of a dollar in advertising expenditure in year $\mathrm{t}-\mathrm{k}(\mathrm{k}=0, \ldots$ $., \mathrm{n})$ to earnings in year $\mathrm{t}$.

To examine the effect of advertising expenditures on financial performance equation (2) is expressed as follow:

Eit $=\alpha 0+\alpha 1$ BVit $+\alpha 2$ ADit $+\alpha 3$ RDit $+\alpha 4 \mathrm{GWit}+\xi$

where the subscript 'it' signifies firm $i$ at time period $t, E$ is earnings, $B V$ is book value, $\mathrm{GW}$ is goodwill, $\mathrm{RD}$ is research and development expenditures, $\mathrm{AD}$ advertising expenditures, and $\xi$ is an error term to allow for potential omitted variables.

If advertising expenditures have asset value $\alpha 2$ should be positive and statistically significant. This provides evidence that advertising expenditures contribute to earnings. We thus form the following hypothesis to test the association between advertising and earnings of the firm:

H1. Advertising expenditures have no association with future earnings.

To examine potential differential media effects on the earnings, we split total advertising expenditures (AD) in equation 3 into print (ADPRN) and electronic (ADEL) media advertising expenditures and estimate the following equation:

Eit $=\alpha 0+\alpha 1 \mathrm{BVit}+\alpha 2 \mathrm{RDit}+\alpha 3 \mathrm{GWit}+\alpha 40 \mathrm{ADPRNit}+\alpha 50 \mathrm{ADELit}+\xi$

To investigate the relative importance of different media in advertising-earnings relation we form the following hypothesis:

H2. Print and electronic media advertising expenditures have no association with future earnings.

To examine multi-period rather than single-period effects of advertising we estimate the following model:

Eit $=\alpha 0+\alpha 1$ BVit $+\alpha 2$ RDit $+\alpha 3$ GWit $+\alpha 41$ AD2003it $+\alpha 51$ AD2002it $+\alpha 61$

AD2001it $+\alpha 71$ AD2000it $+\alpha 81$ AD1999it $+\xi$

Where AD2003, AD2002, AD2001, AD2000 and AD1999 are advertising expenditures in years 2003, 2002, 2001, 2000 and 1999 respectively. 
To study multi-period rather than single-period effects of advertising we test the following hypothesis:

H3. The advertising expenditures have no long lived association with earnings.

\section{Data and sample}

We extract data from Datastream and Datastream Worldscope for all variables apart from advertising that is acquired from 'Nielsen Media Research'. Our sample includes a range of companies (from small to large) from different UK industry sectors ${ }^{6}$. The sample consists of those firms reporting positive earnings for each year from 1999 to 2003 . We exclude firms with negative earnings from the sample as relation between advertising and negative earnings is undefined. Table 1 reports descriptive statistics for variables of pooled firms years from 1999 to 2003. The descriptive statistics disclose some degree of skewness in most of the variables.

Table 1: Descriptive statistics

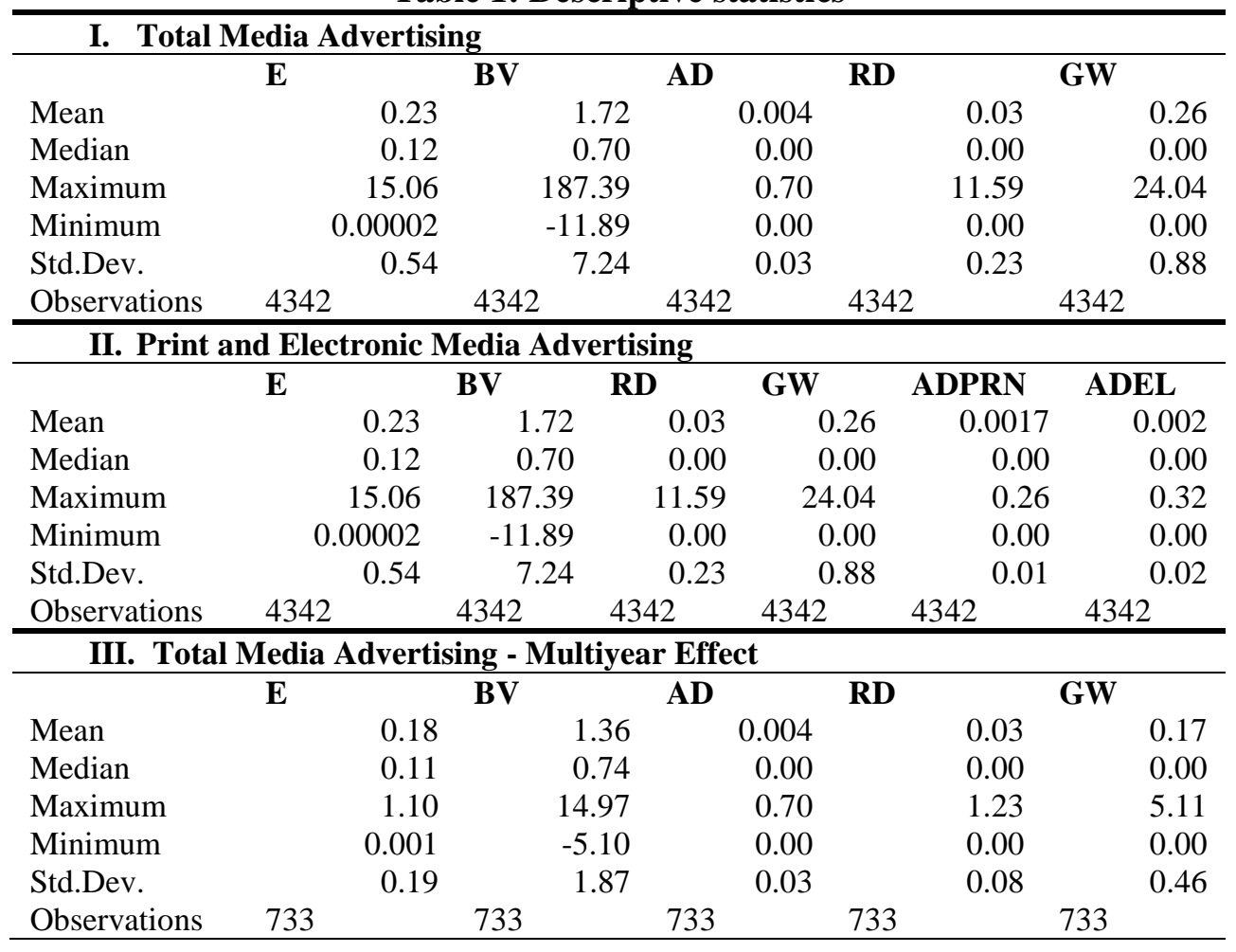

To control heteroscedasticity issue deflation has been used and number of shares (OS) is used as deflator. Correlation matrixes reported in Table 2 confirms that none of the variables is highly correlated with any other in our samples. 
Table 2: Correlation matrix

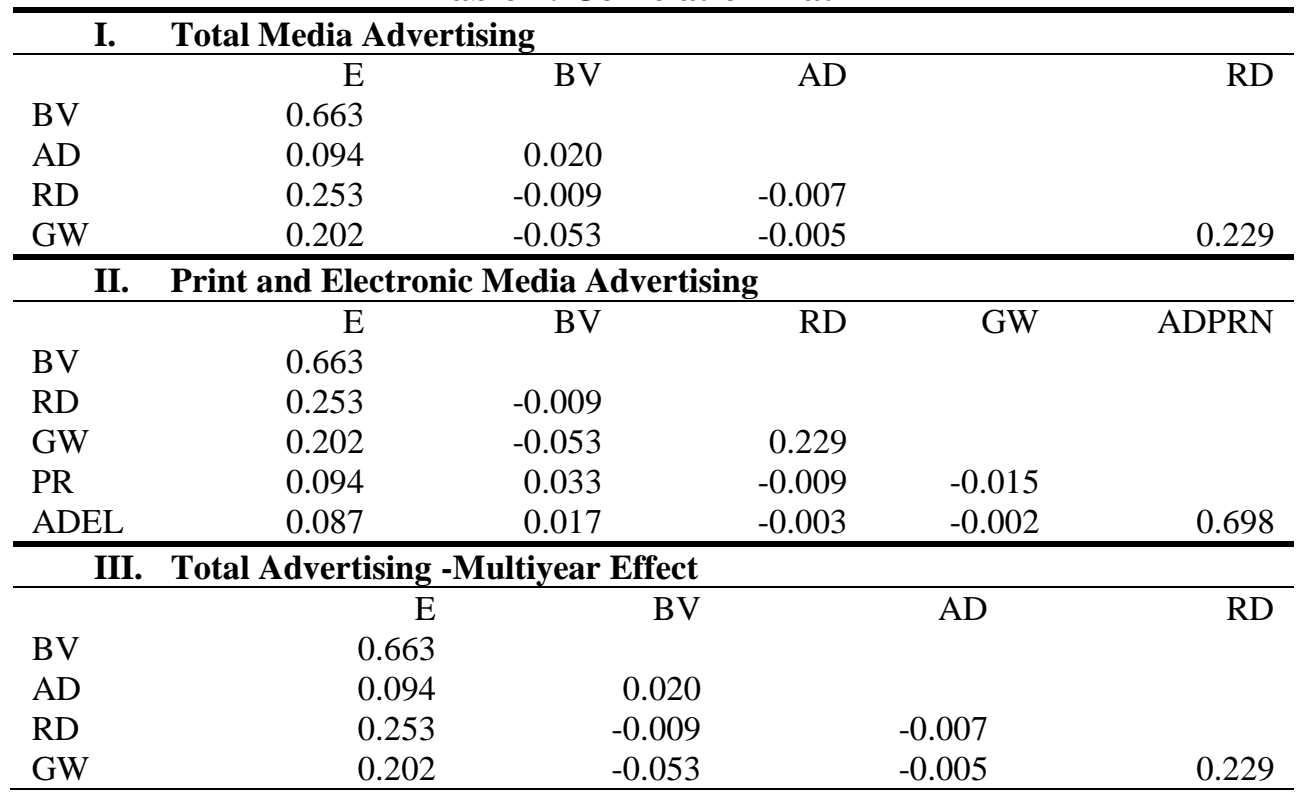

\section{Empirical results}

\section{Total media advertising and earnings - empirical findings model 3}

Model 3 is used to estimate relation between advertising and earnings for the big pooled sample from year 1999 to 2003 and results are presented in Table 3.

Table 3: Model 3 Estimation Results - Pooled Sample (1999-2003)

$$
\mathrm{E}=0.092+0.05 \mathrm{BV}+1.56 \mathrm{AD}+0.52 \mathrm{RD}+0.12 \mathrm{GW}
$$

\begin{tabular}{lrrrrrrr}
\hline Variable & \multicolumn{1}{l}{ Constant } & \multicolumn{1}{l}{ BV } & AD & RD & GW & R $^{\mathbf{2}}$ & Cases \\
\hline Pooled (p & 0.092 & 0.05 & 1.56 & 0.52 & 0.12 & $\mathbf{0 . 5 6}$ & $\mathbf{4 3 4 2}$ \\
value) & $(0.00)$ & $(0.00)$ & $(0.00)$ & $(0.00)$ & $(0.00)$ & & \\
\hline
\end{tabular}

The overall $\mathrm{R}^{2}$ of the pooled sample is 0.56 which means that independent variables explains $56 \%$ of the earnings. Advertising (AD) is the variable of key interest in this study. $\mathrm{AD}$ is positively significantly related to earnings at $1 \%$ level. A positively significant effect of $\mathrm{AD}$ on earnings suggests value relevance of advertising expenditures. Therefore, these findings do no support hypothesis H1. This result is correspondent with Hirschey (1978), Nickell and Metcalf (1978) and Paton and Williams (1999) which report a significantly positive relationship between advertising and profitability. 
The firms use advertising for brand building and promotional purposes. Sridhar et al. (2016) assert that advertising help increase firm performance through brand switching, retention of a large fraction of existing customer base and increased sales among others. We observe in Table 3 that $£ 1$ increase in advertising increases earnings by $£ 1.56$. This indicates that earnings reveal realized benefits from advertising. The coefficient (AD) of total advertising variable in the regression is greater than one which suggest that contribution of advertising to earnings exceeds the nominal value of the expenditure. Graham and Frankenberger (2000) argue that advertising will create value if the present value of this benefit exceeds its cost. These findings show advertising expenditures have significant future economic benefits to the firm which provides justification for investments in advertising to build intangible assets. Chauvin and Hirschey (1993) view advertising expenditures as intangible capital with positive effects on future cash flows and assert that "... data on advertising and R\&D spending appear to help investors form appropriate expectations concerning the size and variability of future cash." Sougiannis (1994) argues that unamortized balances of research and development and advertising expenditures generate capital stock.

The result also shows that other variables in the regression, i.e., BV, RD, and GW, have significant positive effects on earnings. The coefficients of BV, RD and GW are positive and statistically significant at the $1 \%$ significance level.

\section{Print and Electronic Media Advertising and Earnings - Empirical Findings Model 4}

Table 4 reports the effect of print media and electronic media advertising on earnings.

Table 4: Model 4 Estimation Results - Pooled Sample (1999-2003) $\mathrm{E}=0.09+0.05 \mathrm{BV}+0.52 \mathrm{RD}+0.12 \mathrm{GW}+2.14 \mathrm{ADPRN}+1.61 \mathrm{ADEL}$

\begin{tabular}{lrrrrrrll}
\hline Variable & \multicolumn{1}{c}{ Constant } & \multicolumn{1}{l}{ BV } & \multicolumn{1}{l}{ RD } & \multicolumn{1}{c}{ GW } & ADPR & ADEL & R $^{2}$ & Cases \\
\hline $\begin{array}{l}\text { Pooled } \\
\text { (p value) }\end{array}$ & 0.09 & 0.05 & 0.52 & 0.12 & 2.14 & 1.61 & $\mathbf{0 . 5 5}$ & $\mathbf{4 3 4 2}$ \\
\hline
\end{tabular}

The regression 4 is run for the pooled sample where two different levels of accumulation for advertising expenditures, i.e., press and electronic media advertising expenditures, are used to detect their potential differential earnings effects. The estimation results suggest that both print (ADPRN) and electronic media (ADEL) advertising are positively significant at $1 \%$ level. Therefore, these findings do no support hypothesis H2. The estimated coefficient values of ADPRN and ADEL are 2.14 and 1.61 respectively. This indicates that both print and electronic media advertising generate intangible assets for firms. These results contradict findings of Hirschey (1978) and Notta and Oustapassidis (2001) who only find a positive and significant effect of electronic media (television advertising) on profitability of the firms. 
The firms use different media to increase brand awareness, sales, and profitability. We find relatively high effectiveness of print media than electronic media spending. We noted that $£ 1$ increase in print media advertising increases earnings by $£ 2.14$, whereas a $£ 1$ increase in electronic media advertising increases earnings by $£ 1.61$. Macleod (2004) noted that different media advertising outlays varies significantly by country and found television (electronic media) as the most important advertising medium in the US and newspapers (print media) in the UK. In their study Wurff $e t$ $a l$. (2008) provide reasons for these variations such as differences in legislation and industrial structure, marketing traditions and entrepreneurial habits. Our results provide empirical evidence of relative performance effects of print and electronic media that can provide guidance for distribution of advertising expenditures across different media.

The results also illustrate that there is strong correlation among the earnings and GW and RD. The coefficients of both GW and RD are positive and highly significant. The coefficients of other control variable BV is also statistically different from zero. $\mathrm{BV}$ is significantly positively related to earnings. Adjusted $\mathrm{R}^{2}$ for regression 4 is 0.55 .

\section{Multi Period Advertising and Earnings - Empirical Findings Model 5}

Hypothesis 3 tests long lived relationship between advertising and earnings. Table 5 presents the regression 5 results.

Table 5: Model 5 Estimation Results - Pooled Sample (1999-2003)

$\mathrm{E}=0.06+0.06 \mathrm{BV}+0.63 \mathrm{RD}+0.10 \mathrm{GW}+1.26 \mathrm{AD2003}+1.55 \mathrm{AD2002}+$ + 1.97AD2001+ 1.35 AD2000 + 0.84 AD1999

\begin{tabular}{cccccccccccc}
\hline Variable & Const. & \multirow{2}{*}{ BV } & RD & GW & $\begin{array}{c}\text { AD } \\
\mathbf{2 0 0 3}\end{array}$ & $\begin{array}{c}\text { AD } \\
\mathbf{2 0 0 2}\end{array}$ & $\begin{array}{c}\text { AD } \\
\mathbf{2 0 0 1}\end{array}$ & $\begin{array}{c}\text { AD } \\
\mathbf{2 0 0 0}\end{array}$ & $\begin{array}{c}\text { AD } \\
\mathbf{1 9 9 9}\end{array}$ & \multirow{2}{*}{ Cases } \\
\hline $\begin{array}{c}\text { Pooled } \\
\text { (p value) }\end{array}$ & 0.06 & 0.06 & 0.63 & 0.10 & 1.26 & 1.55 & 1.97 & 1.35 & 0.840 .44 & 733 \\
\hline
\end{tabular}

The results show long advertising assets lives. The results indicate that advertising expenditures contribute to earnings up to 4 years following the year of the expenditure. The estimated coefficients of AD2003, AD2002, AD2001, AD2000 and AD1999 are positive and highly significant at $1 \%$ level and in all these years lagged advertising effects are identified. The adjusted $\mathrm{R}^{2}$ of the pooled sample is 0.44 which means that independent variables explains $44 \%$ of the earnings.

In our sample advertising expenditures impacts earnings for up to 5 years and the coefficients of advertising variables range from 0.84 in 1999 to 1.97 in 2001 with an overall mean of 1.39. This denotes that one pound expenditure in advertising will on average contribute $£ 1.39$ to earnings over the five years period. The 2003 year expenditures will contribute to earnings for 4 other years, 2002 year expenditures 
will contribute 3 more years, 2001year expenditures will contribute 2 other years and 1999 year expenditures will contribute 1 more year. In year 2003, by $£ 1$ investment in advertising over the period 1999-2003, the firm recognized benefits of $£ 1.26$ from 2003 investment, £ 1.55 from 2002 investment, 11.97 from 2001 investment, $£ 1.35$ from 2000 investment and $£ 0.84$ from 1999 investment. The total benefit realized over the period from 1999-2003 add to $£$ 6.97. Lev and Sougiannis (1996) compute annual amortization rate of research and development (RD) capital for a given year as the ratio of that's year benefits expired to total benefits.

We expand Lev and Sougiannis (1996) definition to advertising capital to calculate annual amortization rates over the period 1999 to 2003 . For the UK firms advertising expenditures amortization rate for 2003 was $18.10 \%$ (1.26/6.97), for 2002 was $22.20 \%(1.55 / 6.97)$, for 2001 was $28.30 \%(1.97 / 6.97)$, for 2000 was $19.4 \%$ $(1.35 / 6.97)$ and for 1999 was $12.00 \%(0.84 / 6.97)$. Regression results provide general evidence of durability of advertising expenditures which are significantly associated with earnings for more than one period. The results indicate that advertising expenditures offer economic benefits lasting more than one year. The results in regression 5 suggests that advertising expenditures have at least average 5 years asset life. This result is in line with Graham and Frankenberger (2000) who report that advertising expenditures are significantly associated with earnings for more than one year and with Hirschey and Weygandt (1985) who suggest one to five years life of advertising.

\section{Conclusion}

In this study we estimate the relation between the UK firms advertising expenditures and subsequent earnings for the period from 1999 to 2003 and offer further evidence for the asset value of advertising outlays. We find a positive and significant long run association between advertising expenditures and earnings. Our results provide evidence regarding durability of advertising expenditures which contributes to earnings up to four years following the year of the expenditure. This study also offers empirical evidence of the likely differential media effects by dividing total advertising into print, and electronic media advertising. The empirical evidence suggests a significant positive relationship between different measures of advertising expenditures and the firm earnings. From the analysis we can infer that the effectiveness of advertising does not vary significantly with the type of medium used to convey it.

All in all these results lessen the argument that which media advertising should be considered as an intangible asset investment and may be of interest to those policy makers and standard setters. Advertising expenditures effect on earnings of firms in different sectors, and of different sizes can be verified in future research. 


\section{References}

Abbott, A. J., Lawler, K. A. \& Ling, M. C. H. (1997) “Advertising investments in the UK brewing industry: an empirical analysis", Economic Issues, vol. 2: $55-66$

Bublitz, B., \& Ettredge, M. (1989) "The information in discretionary outlays: advertising, research and development", The Accounting Review, vol. LXIV (1): $108-124$

Chauvin, K. W. \& Hirschey, M. (1993) "Advertising, R\&D expenditures and the market value of firms", Financial Management, vol. 22 (4): 128-140

Chauvin, K. W. \& Hirschey, M. (1994) "Goodwill, profitability, and the market value of the firm", Journal of Accounting and Public Policy, vol.13 (2): $159-180$

Chen, H. C. K. \& Allmon, D. (1998) "Perceptions of the media in three different cultures: the US, Australia \& Taiwan", International Journal of Advertising, vol. 17 (2):233-253

Comanor, W. S. \& Wilson, T. A. (1967) "Advertising market structure and performance", The Review of Economics and Statistics, vol. 49 (4): 423-440

Confidence, W. A. (2005) "Advertising expenditure and firm profitability: an investigation", Academy of Marketing Studies Journal, vol. 9 (1-2): 3-20

Connolly, R. A. \& Hirschey, M. (1984) "R\&D, market structure and profits: a valuebased approach", The Review of Economic and Statistics, vol. 66 (4): 682-686

Connolly, R. A.\& Hirschey, M. (1990) "Firm size and R\&D effectiveness: a valuebased test", Economics Letters, vol. 32 (3): 277-281

Core, J. E., Guay, W.R. \& Buskirk, A.V. (2003) "Market valuations in the new economy: an investigation of what has changed", Journal of Accounting and Economics, vol.34: 43-67

Elliott, C. (2001) "A cointegration analysis of advertising and sales data", Review of Industrial Organization, vol. 18: 417-426

Erickson, G. \& Jacobson, R. (1992) "Gaining comparative advantage through discretionary expenditures: the returns to $\mathrm{R} \& \mathrm{D}$ and advertising", Management Science, vol.38: 1264-1279

Graham, R. C. Jr. \& Frankenberger. K. D. (2000) "The contribution of changes in advertising expenditures to earnings and market values", Journal of Business Research, vol. 50: 149-155

Hirschey, M. (1978) "Television advertising and profitability", Economics Letters, vol. 1 (3): 259-264

Hirschey, M. (1982) "Intangible capital aspects of advertising and R\&D expenditures", The Journal of Industrial Economics, vol. 30(4): 375-390

Hirschey, M. (1985) "Market structure and market value", Journal of Business, vol.58 (1): 89-98 
Hirschey, M. \& Spencer, R. S. (1992) "Size effects in the market valuation of fundamental factors", Financial Analysts Journal, (March-April): 91-96

Hirschey, M. \& Weygandt, J. J. (1985) "Amortisation policy for advertising and research and development expenditures", Journal of Accounting Research, vol. 23(1): 326-335

Hula, D.G. (1988) “Advertising, new product profit expectations, and firm's R\&D investment decisions", Applied Economics, vol. 20:125-142

Joshi, A. \& Hanssens, D. M. (2010) "The direct and indirect effects of advertising spending on firm value", Journal of Marketing, vol. 74 (10): 20-33

Lev, B. \& Sougiannis, T. (1996) "The capitalization, amortization, and value relevance of R\&D", Journal of Accounting and Economics, vol. 21: 107-138.

Macleod, C. (2004) "Global adspend trends", International Journal of Advertising, vol. 23(4): 534-536

Mcllkenny, P. \& Persaud, A. (2017) "Value relevance of the voluntary disclosure of advertising expenditure: evidence from Canada", International Journal of Accounting and Finance, vol. 7(3): 185-2018

Megna, P. \& Muller, D. C. (1991) "Profit rates and intangible capital", The Review of Economics and Statistics, vol. 73: 632-642

Nakamura, L. (2005) "Underestimating advertising: innovation and unpriced entertainment", Federal Reserve Bank of Philadelphia Business Review, Q4: 21-29

Nickell, S. \& Metcalf, D. (1978) "Monopolistic industries and monopoly profits or, are Kellogg's cornflakes overpriced?," Economic Journal, vol.88: 254-68

Notta ,O. \& Oustapassidis, K. (2001) "Profitability and media advertising in Greek food manufacturing industries", Review of Industrial Organization, vol. 18: $115-126$

Ouyang, M., Zhou, D. and Zhou, N. (2002) "Estimating marketing persistence on sales of consumer durables in China", Journal of Business Research, vol. 55 : $337-342$

Picconi, M.J. (1977) "A reconsideration of the recognition of advertising assets on the financial statements", Journal of Accounting Research, vol.15: 317-326

Porter, M. E. (1976)" Interbrand Choice, Media mix and market performance", The American Economic Review, vol. 66 (2): 398-406

Qureshi, M. I. (2015) "Valuation of various media advertising expenditures - UK perspective". The International Journal of Accounting, Auditing and Performance Evaluation, vol. 11(1): 1-13

Qureshi, M. I. (2017) "The value relevance of intangibles: some evidence on industry sector, firm performance and size effects", The International Journal of Accounting, Auditing and Performance Evaluation, vol. 13(3): 293-307

Reekie, W.D. \& Bhoyrub, P. (1981) "Profitability and intangible assets: another look at advertising and entry barriers", Applied Economics, vol. 13: 99-107 
Shah, S.Z.A, \& Akbar, S. (2008) "Value relevance of advertising expenditure: a review of the literature", International Journal of Management Reviews, vol. 10 (4): 301-325

Shah, S.Z.A., Stark, A. W. \& Akbar, S. (2009) "The value relevance of major media advertising expenditure: some UK evidence: “, The International Journal of Accounting, vol. 44: 187-206

Sougiannis, T. (1994) "The accounting based valuation of corporate R\&D", Accounting Review, vol. 69: 44-68

Sridhar, S., Germann, F., Kang C., \& Grewal, R. (2016) "Relating online, regional, and national advertising to firm value", Journal of Marketing, vol. 80: 39-55

Wurff, R., Bakker, P. \& Picard, G. R. (2008) "Economic growth and advertising expenditures in different media in different countries", Journal of Media Economics, vol. 21(1): 28-52

Wyatt, A. (2008) "What financial and non-financial information on intangibles is value-relevant? A review of the evidence", Accounting and Business Research, vol. 38(3): 217-256

Yiannaka, A., Giannakas K. \& Tran, K. C. (2002) "Medium, message, and advertising effectiveness in the Greek processed meat industry", Applied Economics, vol. 14:1757-1763

Zhou, N., Zhou, D. \& Ouyang, M. (2003) "Longterm effects of television advertising on sales of consumer durables and nondurables", Journal of Advertising, vol. 32: $45-54$

${ }^{1}$ https://www.statista.com/statistics/273736/advertising-expenditure-in-the-worlds-largest-admarkets/

${ }^{2}$ https://www.statista.com/topics/1747/advertising-in-the-united-kingdom/

${ }^{3} \mathrm{http} / / /$ expenditurereport.warc.com/FreeContent/AA-WARC\%20FY2017.pdf

${ }^{4}$ Wyatt (2008) reports that advertising expenditures are not available in the UK while these are variably disclosed in the US.

${ }^{5}$ UK firms have a discretion to disclose advertising expenditures in financial statements.

${ }^{6}$ Both financial and insurance firms are excluded from the sample for standard reasons. 